\title{
Effects of Hyperoxia on Thermoregulatory Responses during Feet Immersion to Hot Water in Humans
}

\author{
Kazuaki Yamashita and Yutaka Tochihara \\ Department of Ergonomics, Kyushu Institute of Design
}

\begin{abstract}
This study examined effects of hyperoxia on thermoregulatory responses. Eight healthy male students $(23.5 \pm 1.8 \mathrm{yrs})$ were involved in this study. They immersed their legs in a hot water bath $\left(42^{\circ} \mathrm{C}\right)$ for 60 minutes in a climate chamber. The conditions of oxygen concentration of a chamber were set at $21 \%$ (control), $25 \%\left(25 \% \mathrm{O}_{2}\right)$, and $30 \%\left(30 \% \mathrm{O}_{2}\right)$. Ambient temperature and relative humidity was maintained at $25^{\circ} \mathrm{C}$ and $50 \%$ in every condition, respectively. Measurements included rectal temperature (Tre), skin temperature at 7 sites, laser Doppler flowmeter (LDF) on the back and forearm as an index of skin blood flow, heart rate, local sweat rate (Msw) on the back and forearm, and total body weight loss (BWL). Increases of Tre at $25 \% \mathrm{O}_{2}$ and $30 \% \mathrm{O}_{2}$ tended to be lower during the immersion than in the control. Mean skin temperature $(\bar{T} \mathrm{sk})$ of the control increased gradually after the onset of sweating, while the $\bar{T}_{\text {sks }}$ at $25 \% \mathrm{O}_{2}$ and $30 \% \mathrm{O}_{2}$ maintained a constant level during sweating. LDFs on the forearm at $25 \% \mathrm{O}_{2}$ and $30 \% \mathrm{O}_{2}$ showed lower increases compared with the control. No significant differences in Msw on the back and the forearm and BWL were seen among the conditions. These results suggested that hyperoxia could not affect sweating responses but elicit an inhibitory effect on thermoregulatory skin blood flow. J Physiol Anthropol Appl Human Sci 22 (4): 181-185, 2003 http: //www.jstage.jst.go.jp/en/
\end{abstract}

Keywords: hyperoxia, thermoregulation, heat exposure, skin blood flow, sweat rate

\section{Introduction}

Many reports have described the effects of hyperoxia on blood flow at various sites of the body. In previous studies, the effects of hyperoxia on blood flow in humans were observed as an increase in peripheral vascular resistance (Eggers et al. 1962; Crawford et al. 1997; Milone et al. 1999; Mak et al. 2002), reduction of blood flow on the forearm (Milone et al. 1999), brain (Nakajima et al. 1983), and thigh during exercise (Welch et al. 1977). This hyperoxic vasoconstriction (HV) has also been reported in isolated vessels (Carrier et al. 1964;
Messina et al. 1994; Pries et al. 1995; Mouren et al. 1997). Messina et al. (1994) demonstrated that diameter of isolated rat skeletal muscle arterioles decreased by $37 \%$ during the rise in oxygen tension of perfusate from 20 to $150 \mathrm{mmHg}$, with an additional decrease by $14 \%$ from 150 to $660 \mathrm{mmHg}$. These results indicate that hyperoxia could cause a reduction of systemic blood flow. Interestingly, Tomita et al. (1995) reported that vascular endothelial cells dilated and constricted during exposure to $0 \%$ and $100 \% \mathrm{O}_{2}$ stimulus, respectively. Moreover, they suggested that oxygen tension may contribute to capillary autoregulation of blood flow in the microvascular network.

Since the skin microvascular network consists of a rich microvascluar bed, it was thought that hyperoxia could inhibit thermoregulatory blood flow in the skin. Additionally, the hyperoxic inhibition of skin blood flow may affect other thermoregulatory responses. There are, however, few reports on effects of hyperoxia on thermoregulatory responses. Therefore, the present study aimed at examining effects of hyperoxia on thermoregulatory responses in humans.

\section{Methods}

\section{Subjects}

Eight healthy male students $(23.5 \pm 1.8 \mathrm{yrs})$ were involved in this study. The purpose and procedure of the study were explained to each student before the experiments, and they consented to participate in the study voluntarily and were required to wear only shorts during the experiments.

\section{Procedures}

A climate chamber in which oxygen concentration $\left(\mathrm{PO}_{2}\right)$ in air could be controlled independently under normal air pressure was prepared for the experiments. The conditions of $\mathrm{PO}_{2}$ were set at $21 \%$ (control), $25 \%\left(25 \% \mathrm{O}_{2}\right)$, and $30 \%$ $\left(30 \% \mathrm{O}_{2}\right)$. Ambient temperature and relative humidity was controlled at $25^{\circ} \mathrm{C}$ and $50 \%$, respectively. First, the subjects entered the climate chamber and sat for at least 20 minutes. After checking the stability of rectal and skin temperature, the subjects sat for 10 more minutes in order to measure resting states. Thereafter, for $60 \mathrm{~min}$ they immersed their legs in a hot 
water bath maintained at $42^{\circ} \mathrm{C}$. Each subject was exposed to three $\mathrm{PO}_{2}$ conditions randomly and blindly on different days.

\section{Measurements}

Measurements included rectal temperature (Tre), skin temperature at 7 sites (forehead, chest, back, forearm, hand, thigh, and foot), laser Doppler flowmeter (LDF) on the back $(\mathrm{LDFb})$ and forearm (LDFf), heart rate (HR), local sweat rates on the back (Mswb) and forearm (Mswf), and total body weight loss (BWL). For measurement of Tre, the subjects inserted a thermistor probe at the depth of $12 \mathrm{~cm}$ from the sphincter muscle. Thermistors were taped on the specified sites with surgical tape in order to measure skin temperature. Data regarding Tre and skin temperature were collected on a portable data logger (Gram, LT-8A) every second. Mean skin temperature $(\bar{T} \mathrm{sk})$ was calculated using the equation described by Shibasaki et al. (1997). Local sweat rate was measured using a ventilated capsule instrument (K\&S, AMU-100II). LDF probes (omega flow, FLO-C1) were applied to adjacent sites to the ventilated capsules. Electrocardiogram (ECG) was obtained via a telemeter (DS-502, Fukuda Denshi). Each output voltage of each electrical device was recorded on a personal computer (PC-286VF, EPSON) at $500 \mathrm{~Hz}$ via an A/D converter (microscience, ADM-5298BPC). In off-line works, $\mathrm{R}-\mathrm{R}$ intervals were obtained from the ECG, and HR was calculated based on R-R intervals. BWL was determined as the gap between the body weight before and after the experiments, obtained by means of a sensitive balance (ID2, Mettler Instrumente) with an accuracy of $\pm 1 \mathrm{~g}$.

\section{Statistics}

All statistical analyses were performed using STATISTICA for Windows ver. 5.1J (StatSoft, Inc.). Data from time-course measurements were evaluated using repeated measures twoway analysis of variance (ANOVA) employing the data taken every 2 minutes. The effect of $\mathrm{PO}_{2}$ on $\mathrm{BWL}$ was assessed by means of one-way ANOVA. Post-hoc test was performed using Fisher's protected least significant difference for multiple comparisons. Significant differences were established at the $\mathrm{p}<0.05$ level. Each figure is shown as mean values and standard deviation.

\section{Results}

Figure 1 illustrates time course of Tre. Two-way ANOVA revealed a significant main effect of time $(F(34,238)=98.51$, $\mathrm{p}<0.001)$ and interaction between conditions and time $(\mathrm{F}(68,476)=2.28, \mathrm{p}<0.001)$ on Tre. Although Tre rose due to immersion in every condition, the increase in Tre at $25 \% \mathrm{O}_{2}$ and $30 \% \mathrm{O}_{2}$ was smaller than that of the control. The time course of $\bar{T}$ sk is shown in Figure 2. Two-way ANOVA revealed a significant main effect of time $(F(34,238)=12.12, p<0.001)$ and interaction between conditions and time $(\mathrm{F}(68,476)=1.48$, $\mathrm{p}<0.05)$ on $\bar{T}$ sk. $\bar{T}$ sks of $25 \% \mathrm{O}_{2}$ and $30 \% \mathrm{O}_{2}$ decreased from the onset of sweating and then maintained a constant level

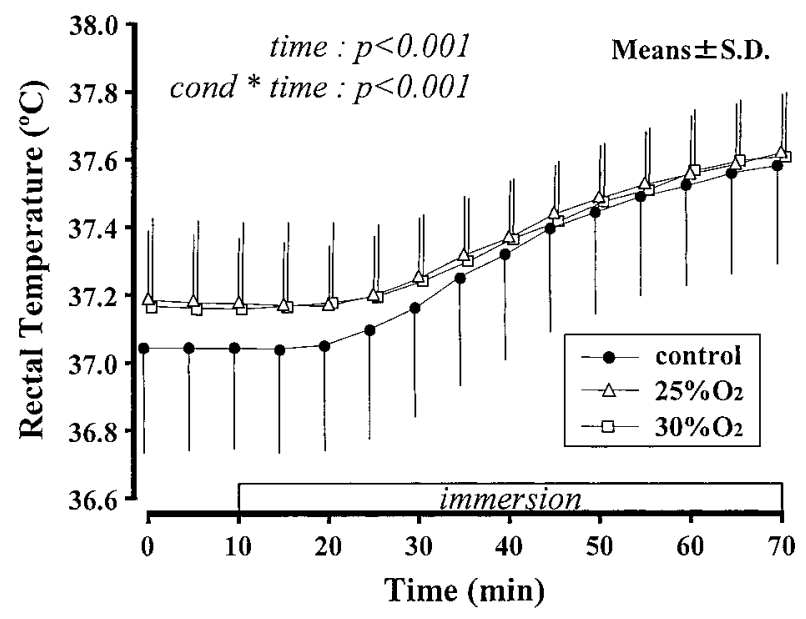

Fig. 1 Time course of rectal temperature of control, $25 \% \mathrm{O}_{2}$ and $30 \% \mathrm{O}_{2}$. Values are means $\pm \mathrm{SD}$. "time: $p<0.01$ " indicates a significant main effect of time. "cond * time: $p<0.01$ " indicates a significant interaction between conditions and time.

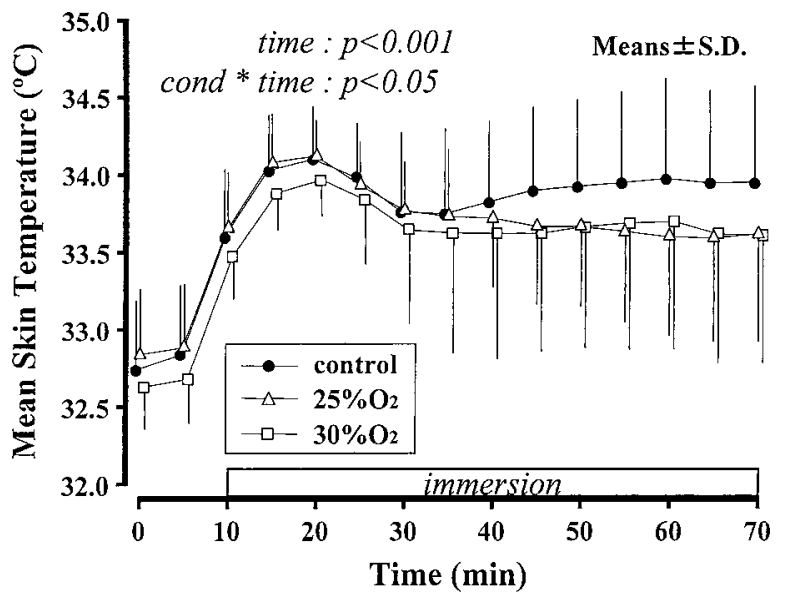

Fig. 2 Time course of mean skin temperature of control, $25 \% \mathrm{O}_{2}$ and $30 \% \mathrm{O}_{2}$. Values are means $\pm \mathrm{SD}$. "time: $p<0.01$ " indicates a significant main effect of time. "cond * time: $p<0.05$ " indicates a significant interaction between conditions and time.

during the immersion, while the $\bar{T}$ sk of the control increased gradually after the onset of sweating. Figure 3 illustrates the time course of LDFb, LDFf, Mswb, and Mswf. As the results of two-way ANOVA, a significant interaction between conditions and time was observed on $\operatorname{LDFf}(\mathrm{F}(68,476)=1.54$, $\mathrm{p}<0.01$ ), while no significant interaction was seen between conditions and time on LDFb, Mswb, and Mswf. LDFfs of $25 \% \mathrm{O}_{2}$ and $30 \% \mathrm{O}_{2}$ tend to increase to a lesser degree than that of the control. The immersion elicited an increase of HR of $18.3 \pm 7.3 \mathrm{bpm}, 15.4 \pm 8.0 \mathrm{bpm}$, and $17.6 \pm 4.8 \mathrm{bpm}$ in the control, and at $25 \% \mathrm{O}_{2}$, and $30 \% \mathrm{O}_{2}$, respectively, but a noticeable difference was not observed in HR. BWL of each condition was $270.3 \pm 65.8 \mathrm{~g}$ in the control, $252.4 \pm 56.2 \mathrm{~g}$ in $25 \% \mathrm{O}_{2}$ and $259.0 \pm 59.5 \mathrm{~g}$ in $30 \% \mathrm{O}_{2}$, while no significant differences were seen regarding BWL. 

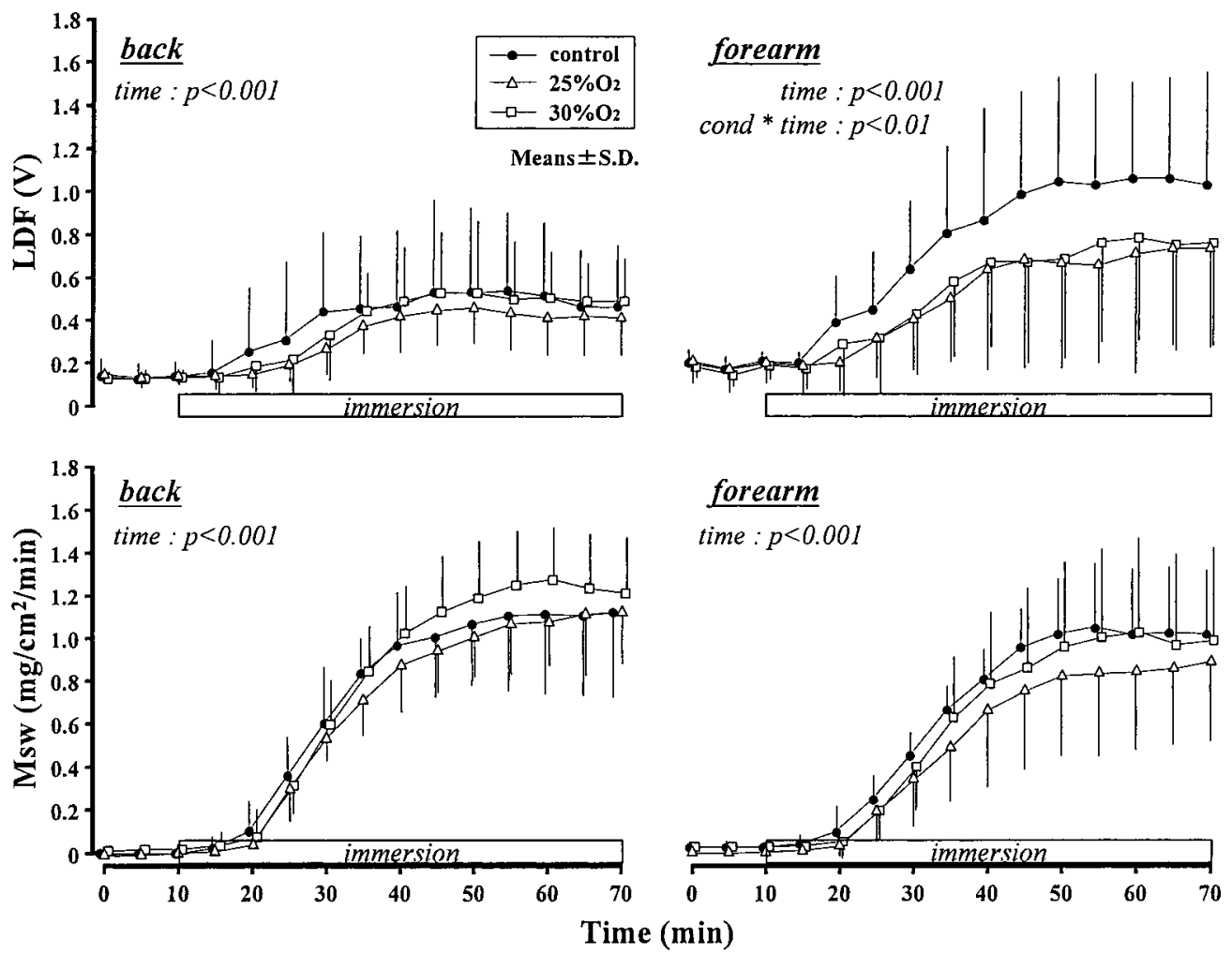

Fig. 3 Time course of $\mathrm{LDF}$ and local swear rate on the back and forearm of control, $25 \% \mathrm{O}_{2}$ and $30 \% \mathrm{O}_{2}$. Values are means $\pm \mathrm{SD}$. "time: $p<0.01$ " indicates a significant main effect of time. "cond $*$ time: $p<0.01$ " indicates a significant interaction between conditions and time.

\section{Discussion}

Several reports have described the effects of hyperoxia on sweat rate. Hubbard and Weiner (1969) showed that there were no significant differences in the forearm sweat rate between breathing $10.5 \%$ and $100 \% \mathrm{O}_{2}$ under 2ATA. Dikshit et al. (1980) demonstrated that there were no significant changes in the whole body sweat rate during $100 \% \mathrm{O}_{2}$ breathing compared with ordinary air breathing under an extremely hot environment of $57^{\circ} \mathrm{C}$. On the other hand, Iyer et al. (1983) showed a significant increase in the forearm sweat rate by breathing $100 \% \mathrm{O}_{2}$ under the same thermal condition as reported by Dikshit et al. (1980), although no significant differences were observed regarding whole body sweat rate. The present study's results regarding forearm sweat rate are consistent with the results reported by Hubbard and Weiner (1969), but not those of Iyer et al. (1983). This discrepancy may depend on the difference of thermal condition, i.e., the thermal stress involved in the study by Iyer et al. (1983) was considerably higher compared with that of the present study. In fact, whole body sweat rate reported by Iyer et al. (1983) was $531 \pm 145 \mathrm{~g}$ and $543 \pm 143 \mathrm{~g}$ in normal air and $100 \% \mathrm{O}_{2}$ breathing, respectively, which is about twice that of the BWL observed in the present study.

A major point of interest in the present study regards the effects of hyperoxia on thermoregulatory skin blood flow. Many researchers have assessed HV at various sites of the body during rest. Milone et al. (1999) reported a significant decrease of forearm blood flow during breathing $100 \% \mathrm{O}_{2}$ in comparison to breathing normal air. Some researchers have also shown similar hyperoxic effects on forearm blood flow (Eggers et al. 1962; Mak et al. 2002). Additionally, reports have described the reduction of blood flow during hyperoxia in the calf (Reich et al., 1970; Hansen and Madsen, 1973), in the retina (Dallinger et al. 2000), the brain (Nakajima et al. 1983), and the subcutaneous adipose tissue (Hansen et al. 1976). The mechanisms of $\mathrm{HV}$ have been discussed from various standpoints. One potential mechanism may be a dysfunction of endothelium-derived relaxing factors (EDRF) by reactive oxide species (Rubanyi and Vanhoutte 1986). On the other hand, recent studies revealed that nitric oxide (NO), which is an EDRF, played a critical role in thermoregulatory skin vasodilatation (Dietz et al. 1994; Shastry et al. 1998; Kellogg Jr. et al. 1998; Schmid et al. 1998; Shastry et al. 2000). If HV brings about a dysfunction regarding NO, it is conceivable that thermoregulatory skin blood flow also suffers from hyperoxia. However, Mouren et al. (1997) suggested that HV was not eliminated by inhibition of NO synthesis in vitro. Hence, it is unlikely that $\mathrm{HV}$ is caused by $\mathrm{NO}$ dysfunction alone.

In the present study, $\bar{T}$ sks at $25 \% \mathrm{O}_{2}$ and $30 \% \mathrm{O}_{2}$ maintained lower levels than did the control as shown in Figure 2, and increase in LDFf was smaller at $25 \% \mathrm{O}_{2}$ and $30 \% \mathrm{O}_{2}$ compared with the control (Fig. 3). Since there were no significant differences between local sweat rate and BWL, it was 
estimated that evaporative heat loss was approximately equal in each condition. Therefore, lower $\bar{T}$ sks at $25 \% \mathrm{O}_{2}$ and $30 \% \mathrm{O}_{2}$ may be induced by a lower increase of skin blood flow. As shown in Figure 1, increases of Tres at $25 \% \mathrm{O}_{2}$ and $30 \% \mathrm{O}_{2}$ tend to be smaller than in the control. These results may also be interpreted to be elicited by $\mathrm{HV}$, i.e., lower skin blood flows on the lower limbs in $25 \% \mathrm{O}_{2}$ and $30 \% \mathrm{O}_{2}$ may intercept the heat gain from hot water to the limbs.

Previous studies have frequently utilized the method of breathing $100 \% \mathrm{O}_{2}$ to create a hyperoxic condition (e.g., Milone et al. 1999). As an interesting observation of this study is that even $25 \%$ or $30 \% \mathrm{O}_{2}$ breathing could induce $\mathrm{HV}$ in skin blood flow. On the other hand, there were no significant differences in thermoregulatory responses between $25 \% \mathrm{O}_{2}$ and $30 \% \mathrm{O}_{2}$. It is unclear that a gap of $5 \% \mathrm{O}_{2}$ concentration is sufficient to elicit differences in thermoregulation during hyperoxia, or whether the thermoregulatory effects of hyperoxia were saturated in $25 \% \mathrm{O}_{2}$. In order to answer these questions, further study is needed involving higher $\mathrm{O}_{2}$ concentrations.

In summary, lower $\bar{T}$ sk and LDFf were observed at $25 \% \mathrm{O}_{2}$ and $30 \% \mathrm{O}_{2}$ compared with the control. Since there were no significant differences in Mswb, Mswf, and BWL among the conditions, it was estimated that evaporative heat loss in each condition was approximately equal. Therefore, lower $\bar{T}$ sk during hyperoxic conditions may indicate that thermoregulatory skin vasodilatation was inhibited by hyperoxia. In conclusion, it was suggested that the inhibitory effects of hyperoxia on blood flow could not affect sweating responses but thermoregulatory skin blood flow in hyperoxic conditions.

\section{References}

Carrier O Jr, Walker JR, Guyton AC (1964) Role of oxygen in autoregulation of blood flow in isolated vessels. Am J Physiol 206: 951-954

Crawford P, Good PA, Gutierrez E, Feinberg JH, Boehmer JP, Silber DH, Sinoway LI (1997) Effects of supplemental oxygen on forearm vasodilation in humans. J Appl Physiol 82: $1601-1606$

Dallinger S, Dorner GT, Wenzel R, Graselli U, Findl O, Eichler HG, Wolzt M, Schmetterer L (2000) Endothelin-1 contributes to hyperoxia-induced vasoconstriction in the human retina. Invest Ophthalmol Vis Sci 41: 864-869

Dietz NM, Rivera JM, Warner DO, Joyner MJ (1994) Is nitric oxide involved in cutaneous vasodilation during body heating in humans? J Appl Physiol 76: 2047-2053

Dikshit MB, Mahmood AM, Iyer EM (1980) Attenuation of heat induced physiological strain by $100 \%$ oxygen breathing. Aviat Med 24: 61-67

Eggers GWN Jr, Paley HW, Leonard JJ, Warren JV (1962) Hemodynamic responses to oxygen breathing in man. $\mathrm{J}$ Appl Physiol 17: 75-79

Hansen M, Madsen J (1973) Estimation of relative changes in resting muscle blood flow by ${ }^{133} \mathrm{Xe}$ washout: the effect of oxygen. Scand J Clin Lab Invest 31: 133-139

Hansen M, Jacobsen E, Madsen J (1976) Influence of hypoxia and hyperoxia on subcutaneous adipose tissue blood flow in man. Scand J Clin Lab Invest 36: 655-660

Hermiston RT, Bonde-Petersen F (1975) The influence of varying oxygen tensions in inspired gas on ${ }^{133}$ Xenon muscle clearance and fatigue levels during sustained and dynamic contractions. Eur J Appl Physiol 34: 291-302

Hubbard JL, Weiner JS (1969) Effect of hyperbaric oxygen on human sweat with particular reference to lactate content. J Appl Physiol 27: 715-720

Iyer EM, Dikshit MB, Banerjee PK, Suryanarayana S (1983) $100 \%$ oxygen breathing during acute heat stress: effect on sweat composition. Aviat Space Environ Med 54: 232-235

Kellogg DL Jr, Crandall CG, Liu Y, Charkoudian N, Johnson JM (1998) Nitric oxide and cutaneous active vasodilation during heat stress in humans. J Appl Physiol 85: 824-829

Mak S, Egri Z, Tanna G, Colman R, Newton GE (2002) Vitamin $\mathrm{C}$ prevents hyperoxia-mediated vasoconstriction and impairment of endothelium-dependent vasodilation. Am J Physiol 282: H2414-H2421

Messina EJ, Sun D, Koller A, Wolin MS, Kaley G (1994) Increases in oxygen tension evoked arteriolar constriction by inhibiting endothelial prostaglandin synthesis. Microvasc Res 48: 151-160

Milone SD, Newton GE, Parker JD (1999) Hemodynamic and biochemical effects of $100 \%$ oxygen breathing in humans. Can J Physiol Pharmacol 77: 124-130

Mouren S, Souktani R, Beaussier M, Abdenour L, Arthaud M, Duvelleroy M, Vicaut E (1997) Mechanisms of coronary vasoconstriction induced by high arterial oxygen tension. Am J Physiol 272: H67-H75

Nakajima S, Meyer JS, Amano T, Shaw T, Okabe T, Mortel KF (1983) Cerebral vasomotor responsiveness during 100\% oxygen inhalation in cerebral ischemia. Arch Neurol 40: 271-276

Pries AR, Heide J, Ley K, Klotz KF, Gaehtgens P (1995) Effect of oxygen tension on regulation of arteriolar diameter in skeletal muscle in situ. Microvasc Res 49: 289-299

Reich T, Tuckman J, Naftchi NE, Jacobson JH (1970) Effect of normo- and hyperbaric oxygenation on resting and postexercise calf blood flow. J Appl Physiol 28: 275-278

Rubanyi GM, Vanhoutte PM (1986) Superoxide anions and hyperoxia inactivate endothelium-derived relaxing factor. Am J Physiol 250: H822-H827

Schmid HA, Riedel W, Simon E (1998) Role of nitric oxide in temperature regulation. Prog Brain Res 115: 87-110

Shastry S, Dietz NM, Halliwill JR, Reed AS, Joyner MJ (1998) Effects of nitric oxide synthase inhibition on cutaneous vasodilation during body heating in humans. J Appl Physiol 84: 830-834

Shastry S, Minson CT, Wilson SA, Dietz NM, Joyner MJ (2000) Effects of atropine and L-NAME on cutaneous blood flow during body heating in humans. J Appl Physiol 88: 
$467-472$

Shibasaki M, Inoue Y, Kondo N (1997) Mechanisms of underdeveloped sweating responses in prepubertal boys. Eur J Appl Physiol 76: 340-345

Tomita M, Fukuuchi Y, Tanahashi N, Kobari M, Takeda H, Yokoyama M, Ito D, Terakawa S (1995) Contraction/ dilatation of cultured vascular endothelial cells induced by hyperoxia/hypoxia. J Cereb Blood Flow Metab (suppl.) 15: S271

Welch HG, Bonde-Petersen F, Graham T, Klausen K, Secher N
(1977) Effect of hyperoxia on leg blood flow and metabolism during exercise. J Appl Physiol 42: 385-390

Received: March 3, 2003

Accepted: May 14, 2003

Correspondence to: Kazuaki Yamashita, 4-9-1 Shiobaru, Minami-ku, Fukuoka 815-8540, Japan

Phone: +81-92-553-4522

Fax: +81-92-553-4569

e-mail yam@rms.kyushu-id.ac.jp 